\title{
Aktaş Gölü (Ardahan, Türkiye) kerevitlerinin (Astacus leptodactylus, Eschscholtz, 1823) ağırlık uzunluk ilişkisi ve et verimi
}

\author{
Önder AKSU*, Gülderen KURT KAYA \\ Munzur Üniversitesi Su Ürünleri Fakültesi, Tunceli, Türkiye. \\ Geliş Tarihi (Recived Date): 01.10.2017 \\ Kabul Tarihi (Accepted Date): 23.10.2017
}

\section{Özet}

Bu çalışmada ticari kerevit avcıll̆̆ğnın yasak olduğu Aktaş Gölü'nden yakalanan erkek ve dişi kerevitlerin morfometrik analizlerinin ve et verimlerinin tespit edilmesi amaçlanmıştır. Çalışmada 157 adet kerevitin ( $n_{\text {erkek }}=81$ and $n_{\text {dişi }}=76$ ) boy dağllımı incelendi. Hem erkek ve hem de dişi kerevitlerin karapaks uzunluklart ile ağırlıkları arasında güçlü bir doğrusal ilişkinin olduğu tespit edildi $\left(r_{\bigcirc}=0.962, \quad r_{\odot}=0.976\right.$, $\left.r_{\hat{\delta}+}=0.9712\right)$. Regresyon analizleri sonucunda elde edilen " $b$ değerleri" erkek kerevitlerde pozitif, dişi kerevitlerde negatif ve tüm bireylerde ise pozitif allometrik ăgırlık artışının olduğunu gösterdi $\left(b_{\hat{\delta}}=3.041, b_{+}=2.954\right.$ ve $\left.b_{\hat{O}+}=3.0167\right)$. Erkek ve dişi kerevitlerde abdomen et miktarları ile karapaks uzunlukları arasında doğrusal bir ilişkinin olduğu görüldü. Erkek kerevitlerde abdomen et verimlerinin, kıskaç et verimleri ve toplam et verimlerinin strastyla \%10.03, \% 4.60 ve \%14.63 olduğu, dişi kerevitlerde abdomen et verimlerinin, kıskaç et verimleri ve toplam et verimlerinin sirasıyla \%11.59, \% 2.73 ve \% 14.32 olduğu belirlendi.

Anahtar Kelimeler: Aktaş Gölü, Astacus leptodacylus, kerevit, boy-ağırlık, et verimi.

\footnotetext{
* Önder AKSU, onderaksu@munzur.edu.tr, http://orcid.org/0000-0003-3735-6732

Gülderen KURT KAYA, gkurtkaya@munzur.edu.tr, http://orcid.org/0000-0001-8988-2238
} 


\title{
The relationships between length-weight, and meat yield of freshwater crayfish (Astacus leptodactylus Eschscholtz, 1823) of Aktaş Lake
}

\begin{abstract}
In this study, determination of morphometric analysis and meat yields were aimed in male and female crayfish caught from Aktas Lake, where commercial crayfish hunting is prohibited. The length distribution of 157 crayfish $\left(n_{\text {male }}=81\right.$ and $\left.n_{\text {femal }}=76\right)$ was examined in the study. It was determined that there was a strong linear relationship between carapace length and weight of both male and female crayfish $\left(r_{0}=0.962, r_{\text {o }}\right.$ $=0.976, r+q=0.9712)$. The $" b$ values" obtained as a result of regression analysis showed that male crayfish had positive weight gain, and female crayfish had negative weight gain, and all individuals had positive allometric weight gain ( $b_{0}=3.041, b_{+}=$ 2.954 ve $\left.b_{\delta+q}=3.0167\right)$. It was shown that there was a linear relationship between abdominal meat quantities and carapace lengths of male and female crayfish. Abdominal meat yield, chelae meat yield and total meat yield in male crayfish was $10.03 \%, 4.60 \%$ and $14.63 \%$, respectively, abdominal meat yield, chelae meat yield and total meat yield in female crayfish was $11.59 \%, 2.73 \%$ and $14.32 \%$, respectively.
\end{abstract}

Keywords: Aktaş Lake, Astacus leptodacylus, crayfish, lenght-weight, meat yield.

\section{Giriş}

Kerevitler çoğu ülkede kültürel öneme sahip, asırlardır geleneksel olarak önemli günlerde tüketilen ve pazarda yüksek ekonomik değeri olan kabuklu su canlılarıdır [13]. Kerevit eti yüksek miktarda $\mathrm{Na}, \mathrm{K}, \mathrm{Ca}$ ve $\mathrm{Mg}$ elementleri ve vitamin $\mathrm{B}$, vitamin $\mathrm{C}$ ihtiva eder. Bir çok balık türünden daha fazla karoten içerir ve düşük kalorili bir protein kaynağıdır $[4,5]$.

Astacus cinsine üye olan kerevitler Asya ve Avrupa'da bir çok ülkede yayılım göstermektedirler [6]. Türkiye'nin tek doğal kerevit türü Astacus leptodactylus olarak bilinmektedir, bununla birlikte son yıllarda orta ve güneydoğu Avrupa kökenli bir tür olan Austropotamobius torrentium'un Velika ve Madara derelerinde varlı̆g rapor edilmiştir [7-9]. A. leptodactylus dar kıskaçları ile farklı kerevit türlerinden rahatça ayırt edilebilir ve Türk, Galiçya, bataklık veya gölet kereviti olarak da bilinir [10].

Bir kerevit populasyondan verimli bir şekilde yararlanılmak isteniyor ise populasyon hakkında bilgi edinmek için stok tespiti tek başına yeterli olmayacaktır. Stok tespitinin yanı sıra populasyonun özelliklerinin de belirlenmesi, etkili yönetim planlarının oluşturulması aşamasında önemlidir [11]. Sürdürülebilir bir populasyon yönetimi için seçilecek metotların doğru belirlenmesi gereklidir. Her şarta uygun gelecek genel bir yöntem yoktur ve yapılacak çalışmalar türe, çevresel ortamın özelliklerine ve sosyal özelliklere göre değişiklik gösterebilmektedir. Bu sebeple, bir iyileştirme uygulaması gerçekleştirilmeden önce populasyonu etkileyen ekolojik, ekonomik ve sosyal özelliklerin bilinmesi zorunludur [12-14]. 
Kerevitlerin vücut bölümlerinin uzunluk ölçümleri, türler arasında erkek ve diși kerevitlerin morfolojik farklılarının belirlenmesinde kullanılır [15-17]. Bu ölçümler populasyonların karşılaştırmalı büyümesinin [18, 19], pazara sürülecek kerevit büyüklüğünün, et veriminin tespit edilmesinde ve sistematik ayrımda kullanılmaktadır [20-22].

Yöredeki balıkçılar Aktaş Gölü'ne kerevitin 2006-2008 yılları arasında, Çıldır Gölü'nde avcılık yapan balıkçılar tarafindan getirilerek yasal bir izin olmadan ortama bırakıldığını bildirmektedirler.

$\mathrm{Bu}$ çalışma ile Aktaş Gölü'ndeki erkek ve dişi kerevitlerin morfometrik analizlerinin yapılması ve et verimlerinin tespit edilmesi, amaç edinilmiştir.

\section{Materyal ve metot}

Boy-ağırlık ilişkileri ve et verimleri farklı kerevit populasyonlarının özelliklerinin karşılaştırılmasında kullanılmaktadır. Bu amaçla araştırma Temmuz-Ağustos 2012 tarihleri arasında konum olarak Türkiye-Gürcistan sınırında bulunan, ticari kerevit avcılığının yasak olduğu Aktaş Gölü'nde alınan yasal izin ile yürütülmüştür. Toplam $27 \mathrm{~km}^{2}$ yüzey alanına sahip olan gölün, $14 \mathrm{~km}^{2}$ lik kısmı Türkiye ve $13 \mathrm{~km}^{2}{ }^{\prime \prime l i k ~ k ı s m ı ~ i s e ~}$ Gürcistan sınırları içinde yer alır (Şekil 1) [23].

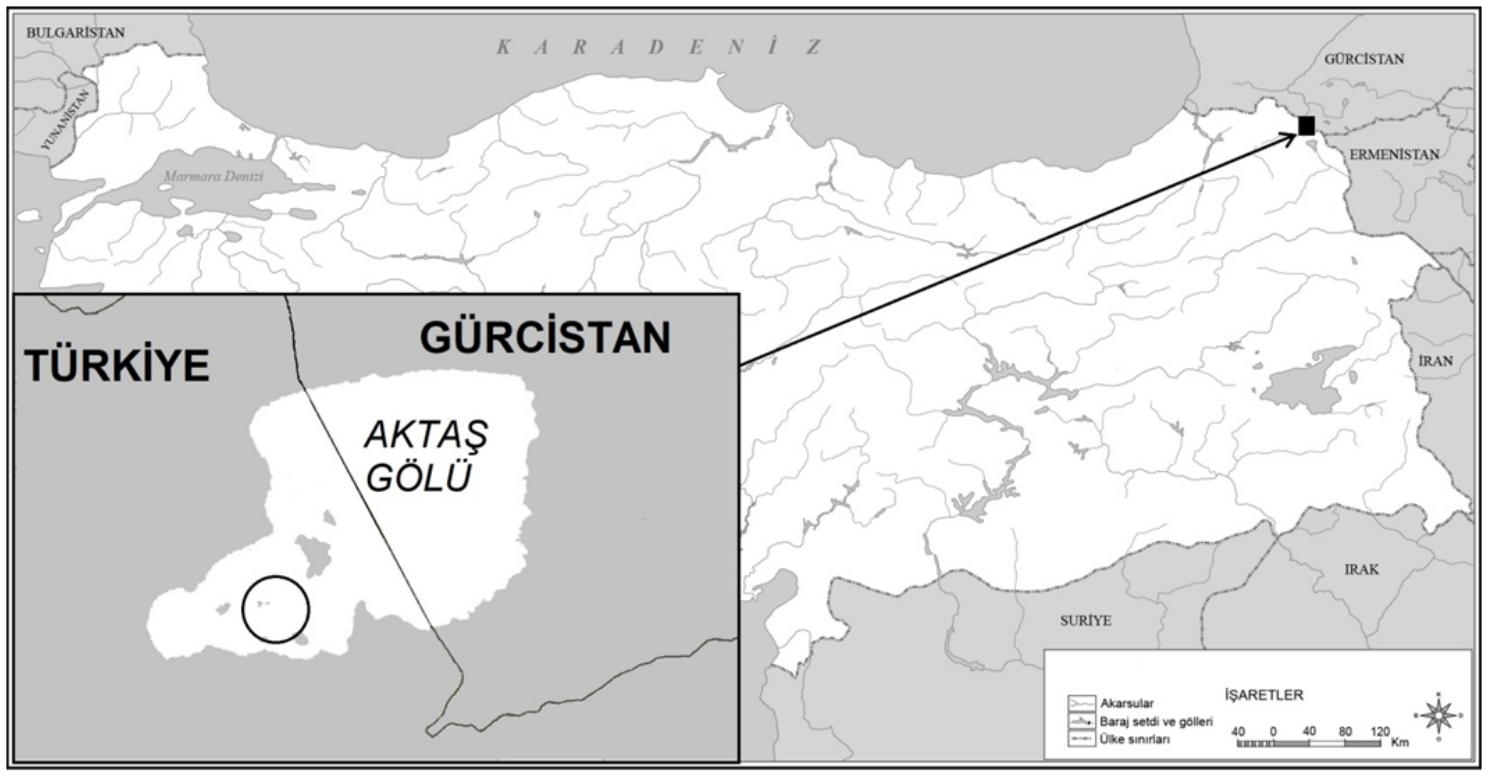

Şekil 1. Aktaş Gölü ve Türkiye'deki konumu (daire ile çevrelenen alan avcılık yapılan bölgeyi göstermektedir) [24].

Çalışma materyali olarak 50 adet pinter ağı kullanılarak avlanan, 75 adet dişi ve 81 adet erkek olmak üzere toplam 156 adet kerevit (A. leptodactylus) kullanıldı.

Avlanan kerevitler içinde buz bulunan kasalarda muhafaza edilerek Munzur Üniversitesi Su Ürünleri Fakültesi laboratuarlarına getirildi. Kerevitlerin uzunluk parametrelerinin ölçümlerinin yapılmasında Rhodes ve Holdich [25]'in uyguladığ yöntem kullanıldı (Şekil 2). Uzunluk ölçümleri milimetre olarak $0.5 \mathrm{~mm}$ hassasiyetli 
kumpas ile ölçüldü. Vücut ağırlıkları 0.1 gr hassasiyetli ve et miktarları 0.01 gr hassasiyetli teraziler ile tartıldı. Kerevitler Harlığlu, [26]'da kullanılan yöntem uygulanarak su içinde 10 dakika süre ile kaynatıldıktan sonra, abdomen ve kıskaçları makasla kesildikten sonra bu kısımlardan etler çıkarılıp ağırlıkları tartıldı. Kerevitlerin et verimleri, abdomen ve kıskaçlardan çıkarılan etlerin ağırlığının toplam vücut ağırlığına oranlanmasıyla belirlendi.

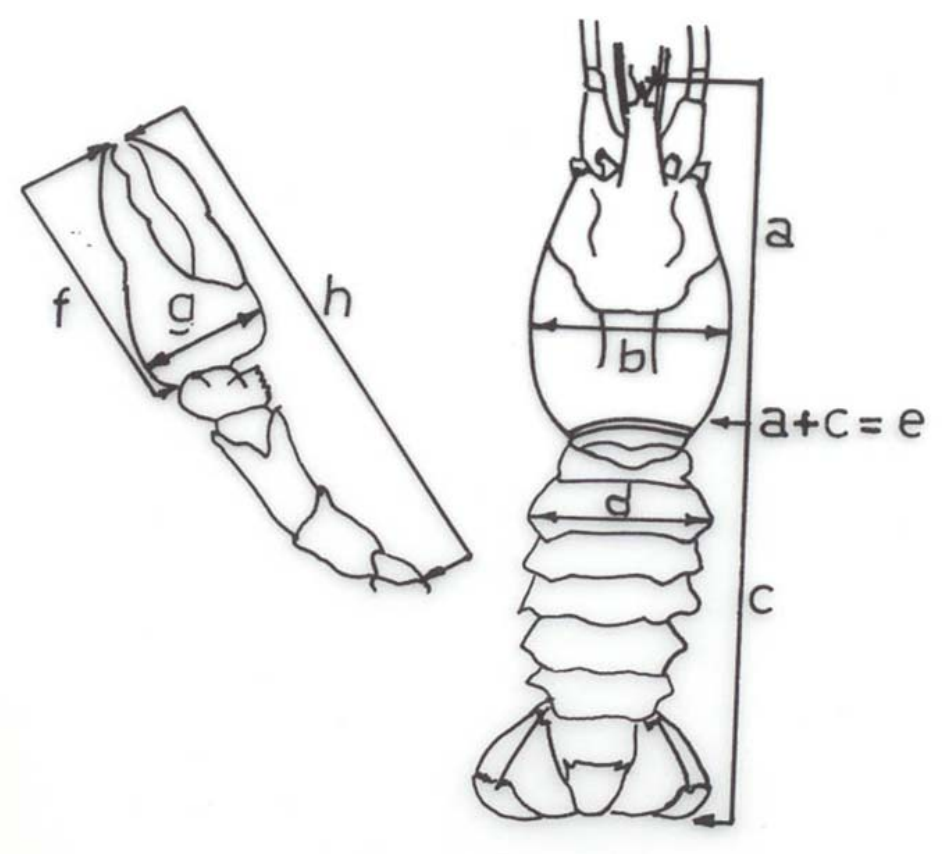

Şekil 2. Kerevitlerde vücut bölümlerine ilişkin belirli ölçümler: a) karapaks uzunluğu, b) karapaks genişliği, c) abdomen uzunluğu, d) abdomen genişliği, e) toplam uzunluk, f) kıskaç uzunluğu, g) kıskaç genişliğii, h) kıskaç ayak uzunluğu [25].

Kabuklu canlıların uzunlukları ile ağırlıkları arasındaki ilişkinin belirlenmesinde genellikle $\log \mathrm{y}=\log (\mathrm{a})+\mathrm{b} \log (\mathrm{x})$ regresyon formülü kullanılmaktadır. Burada " $\mathrm{r}$ " değeri iki ölçüm arasındaki ilişkinin doğrusal durumunu gösterirken, regresyon analizindeki " $b$ " değeri canlının allometrik veya izometrik büyüme durumunu belirtmektedir. Eğer "b değeri" 3'ten büyük ise canlı pozitif allometrik büyüme göstermekte, "b değeri” 3'e eşit ise canlı izometrik büyüme göstermektedir [27].

Erkek ve dişi bireylerin et miktarları ve vücut uzunlukları arasındaki farkın önem derecesi istatistiksel t-testi ile spss 14 bilgisayar yazılımı kullanılarak karşılaştırıldı.

\section{Bulgular}

\subsection{Kerevitlerde boy-ăğırlık ilişkisi}

Çalışmada kerevitlerin 33-75 mm karapaks boyu aralığında dağılım gösterdiği görüldü. Ortalama karapaks boyu dişilerde 53.09 $\pm 9.23 \mathrm{~mm}$ (min: 33-max: $77 \mathrm{~mm}$ ), erkeklerde 59.09 $\pm 10.11 \mathrm{~mm}$ (min: 39-max: $75 \mathrm{~mm}$ ) ve tüm bireylerde $56.18 \pm 10.12 \mathrm{~mm}$ olarak bulundu. Yakalanan kerevitlerin hem erkek ve hem de dişi bireylerde en fazla 56-60 mm karapaks boy grubunda oldukları görüldü. 
Kerevitlerin ağırlık dağılımları incelendiğinde canlı ağırlığın 6.5 g ile 102 g arasında değiştiği ve ortalama ağırlığın 41.82 g olduğu saptand1. Dişi bireylerin ağırlıkları 6.5$94 \mathrm{~g}$ arasında dağılım gösterdi ve dişilerin ortalama ağırlı̆̆ $34.55 \mathrm{~g}$ olarak saptandi. Erkek bireylerin ise ağırlıkları 10.1-102 g arasında bir dağılım gösterdi ve ortalama ağırlıkları $49.09 \mathrm{~g}$ olarak tartıldı (Tablo 1).

Tablo 1. Aynı karapaks uzunluk gruplarındaki erkek ve dişi kerevitlere ait morfometrik ölçümler ve ağırlıkları ( \pm değerler standart sapmaları göstermektedir).

\begin{tabular}{|c|c|c|c|c|c|c|c|c|}
\hline & \multicolumn{8}{|c|}{ Karapaks uzunluk grupları $(\mathrm{mm})$} \\
\hline & $\begin{array}{c}36-40 \\
\mathrm{~N}_{0}^{\hat{n}}=2 \\
\mathrm{~N}+=8\end{array}$ & $\begin{array}{c}41-45 \\
\mathrm{~N}^{-1}=10 \\
\mathrm{~N} \bigcirc=9\end{array}$ & $\begin{array}{l}46-50 \\
\mathrm{~N}_{\hat{O}}^{\hat{n}}=6 \\
\mathrm{~N} \bigcirc=9\end{array}$ & $\begin{array}{c}51-55 \\
\mathrm{~N}^{\hat{\gamma}}=6 \\
\mathrm{~N} Q=13\end{array}$ & $\begin{array}{c}56-60 \\
\mathrm{~N}_{0}^{\hat{n}}=19 \\
\mathrm{~N}_{+}=23\end{array}$ & $\begin{array}{c}61-65 \\
\mathrm{~N}^{\hat{1}}=13 \\
\mathrm{~N} \bigcirc=8\end{array}$ & $\begin{array}{c}66-70 \\
\mathrm{~N}_{0}^{\hat{y}}=12 \\
\mathrm{~N} Q=3\end{array}$ & $\begin{array}{c}71-75 \\
\mathrm{~N}_{0}^{\hat{x}}=13 \\
\mathrm{~N} Q=2\end{array}$ \\
\hline Ağırlık & $11.4 \pm 1.8$ & $16.8 \pm 3.0$ & $23.9 \pm 3.7$ & $32.3 \pm 4.4$ & $43.5 \pm 4.1$ & $55.1 \pm 5.9$ & $66.3 \pm 8.3$ & $85.4 \pm 11.5$ \\
\hline Ağırlık & $12.2 \pm 1.4$ & $17.0 \pm 2.9$ & $24.0 \pm 3.3$ & $33.4 \pm 3.5$ & $41.1 \pm 3.9$ & $52.3 \pm 4.2$ & $56.8 \pm 5.0$ & $92.0 \pm 2.8$ \\
\hline $\begin{array}{c}\text { Karapaks } \\
\text { Uzunluk } \hat{\delta}\end{array}$ & $39.5 \pm 0.7$ & $42.2 \pm 1.4$ & $47.8 \pm 1.5$ & $52.5 \pm 1.4$ & $58.5 \pm 0.9$ & $62.8 \pm 1.4$ & $67.8 \pm 1.5$ & $72.5 \pm 1.6$ \\
\hline $\begin{array}{c}\text { Karapaks } \\
\text { Uzunluk } q \\
\end{array}$ & $37.9 \pm 1.1$ & $43.3 \pm 1.5$ & $48.2 \pm 1.8$ & $53.4 \pm 1.3$ & $57.6 \pm 1.4$ & $62.8 \pm 1.6$ & $67.0 \pm 1.0$ & $77.0 \pm 0.0$ \\
\hline 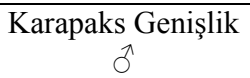 & $19.3 \pm 0.5$ & $21.9 \pm 1.9$ & $24.9 \pm 1.6$ & $27.8 \pm 1.4$ & $31.3 \pm 1.1$ & $33.9 \pm 1.5$ & $36.1 \pm 1.9$ & $39.3 \pm 2.1$ \\
\hline $\begin{array}{l}\text { Karapaks Genişlik } \\
\text { 오 }\end{array}$ & $19.6 \pm 0.7$ & $22.3 \pm 1.5$ & $25.2 \pm 1.5$ & $28.0 \pm 0.7$ & $30.6 \pm 1.2$ & $33.1 \pm 1.9$ & $34.8 \pm 0.3$ & $40.6 \pm 0.8$ \\
\hline $\begin{array}{c}\text { Abdomen } \\
\text { Genişlik ổ }\end{array}$ & $17.4 \pm 1.4$ & $18.5 \pm 1.2$ & $20.6 \pm 1.1$ & $22.9 \pm 0.9$ & $24.9 \pm 1.7$ & $27.2 \pm 1.3$ & $28.5 \pm 1.7$ & $30.6 \pm 1.4$ \\
\hline $\begin{array}{l}\text { Abdomen } \\
\text { Genişlik }{ }_{+}\end{array}$ & $18.1 \pm 1.0$ & $20.1 \pm 1.9$ & $23.8 \pm 1.5$ & $27.5 \pm 2.2$ & $30.6 \pm 1.9$ & $34.3 \pm 3.8$ & $34.8 \pm 0.9$ & $46.9 \pm 3.0$ \\
\hline Kıskaç Uzunluk & $23.2 \pm 1.6$ & $27.2 \pm 2.6$ & $29.4 \pm 3.8$ & $34.9 \pm 2.8$ & $42.4 \pm 2.5$ & $46.9 \pm 4.6$ & $51.8 \pm 3.8$ & $59.9 \pm 8.9$ \\
\hline $\begin{array}{c}\text { Kiskaç Uzunluk } \\
\text { q }\end{array}$ & $21.9 \pm 3.1$ & $24.4 \pm 1.8$ & $27.4 \pm 2.0$ & $32.9 \pm 2.7$ & $36.5 \pm 2.6$ & $39.6 \pm 2.9$ & $43.2 \pm 1.5$ & $53.7 \pm 2.3$ \\
\hline Kıskaç Genişlik $\widehat{~}$ & $7.9 \pm 0.3$ & $10.7 \pm 1.1$ & $12.6 \pm 1.1$ & $13.5 \pm 2.6$ & $16.9 \pm 2.4$ & $17.6 \pm 2.1$ & $18.9 \pm 0.9$ & $22.3 \pm 2.5$ \\
\hline Kıskaç Genişlik ${ }_{+}$ & $9.3 \pm 0.9$ & $10.5 \pm 0.8$ & $11.9 \pm 0.9$ & $14.0 \pm 1.1$ & $15.2 \pm 0.9$ & $16.6 \pm 1.4$ & $17.3 \pm 0.7$ & $20.6 \pm 0.9$ \\
\hline $\begin{array}{c}\text { Kıskaç ayak } \\
\text { Uzunluk } \hat{\delta}\end{array}$ & $52.5 \pm 3.5$ & $57.6 \pm 5.9$ & $67.3 \pm 7.1$ & $70.6 \pm 2.5$ & $80.0 \pm 4.1$ & $87.6 \pm 6.5$ & $96.1 \pm 6.8$ & $\begin{array}{c}103.6 \pm 29 . \\
1\end{array}$ \\
\hline $\begin{array}{l}\text { Kıskaç ayak } \\
\text { Uzunluk } \text { + }\end{array}$ & $42.9 \pm 1.9$ & $53.1 \pm 4.3$ & $57.0 \pm 4.9$ & $65.7 \pm 3.3$ & $72.3 \pm 4.5$ & $79.9 \pm 3.1$ & $80.0 \pm 2.5$ & $102.0 \pm 4.5$ \\
\hline
\end{tabular}

Tablo 2. Erkek ve dişi kerevitlerin morfometrik ölçümlerinin karşılaştırması ve istatistiksel olarak farklılıkları

\begin{tabular}{|c|c|c|c|c|}
\hline & Eşey & $\begin{array}{c}\text { Ortalama (En Küçük ve En Büyük } \\
\text { değerler) }\end{array}$ & $\begin{array}{l}\text { Standart } \\
\text { Sapma }\end{array}$ & İstatistik \\
\hline \multirow{2}{*}{ Karapaks Uzunluk } & $\hat{\sigma}$ & $59.1(39-75)$ & 10.11 & \multirow{2}{*}{$\mathrm{P}<0.001$} \\
\hline & q & $53.1(33-77)$ & 9.23 & \\
\hline \multirow{2}{*}{ Karapaks Genişlik } & $\hat{0}$ & $31.5(19-42)$ & 5.98 & \multirow{2}{*}{$\mathrm{P}<0.001$} \\
\hline & $q$ & $27.9(16-41)$ & 5.15 & \\
\hline \multirow{2}{*}{ Abdomen Genişlik } & $\hat{0}$ & $25.3(16-33)$ & 4.26 & \multirow{2}{*}{$\mathrm{P}<0.05$} \\
\hline & o & $27.5(15-49)$ & 6.61 & \\
\hline \multirow{2}{*}{ Kiskaç Uzunluk } & $\hat{0}$ & $43.5(22-69)$ & 11.87 & \multirow{2}{*}{$\mathrm{P}<0.001$} \\
\hline & q & $32.6(17-55)$ & 7.64 & \\
\hline \multirow{2}{*}{ Kıskaç Genişlik } & $\hat{0}$ & $16.6(8-26)$ & 4.24 & \multirow{2}{*}{$\mathrm{P}<0.001$} \\
\hline & $q$ & $13.7(8-21)$ & 2.91 & \\
\hline \multirow{2}{*}{ Kıskaç ayak Uzunluk } & $\hat{\sigma}$ & $82.3(11-124)$ & 19.62 & \multirow{2}{*}{$\mathrm{P}<0.001$} \\
\hline & 울 & $65.4(40-106)$ & 13.58 & \\
\hline \multirow{2}{*}{ Ağırlık } & $\sigma^{\pi}$ & $49.1(10-102)$ & 23.41 & \multirow{2}{*}{$\mathrm{P}<0.001$} \\
\hline & q & $34.6(7-94)$ & 16.73 & \\
\hline
\end{tabular}


Kerevitlerin morfometrik ölçümleri incelendiğinde, karapaks uzunluğu, karapaks genişliği, kıskaç uzunluğu, kıskaç genişliği, kıskaç ayak uzunluğu ve ağırlık parametrelerinde, erkek kerevitlere ait ölçüm değerlerinin dişilere oranla istatistiksel olarak daha büyük değerlere sahip olduğu belirlendi $(\mathrm{P}<0.001)$. Bununla birlikte, dişi kerevitlere ait abdomen genişliği değerinin ise erkek kerevitlerden istatistiksel olarak daha büyük değerlere sahip olduğu görüldü $(\mathrm{P}<0.05)$ (Tablo 2).

Kerevitlerin karapaks uzunlukları ile ağırlıkları arasındaki ilişki regrasyon analizleri yapılarak incelendi. Ölçümler sonucunda " $r$ " değerlerine bakıldığında, hem erkek ve hem de dişi kerevitlerin karapaks uzunlukları ile ağırlıkları arasında güçlü bir doğrusal

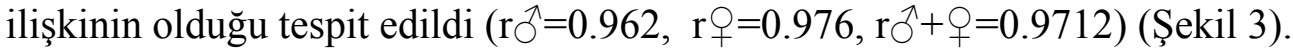

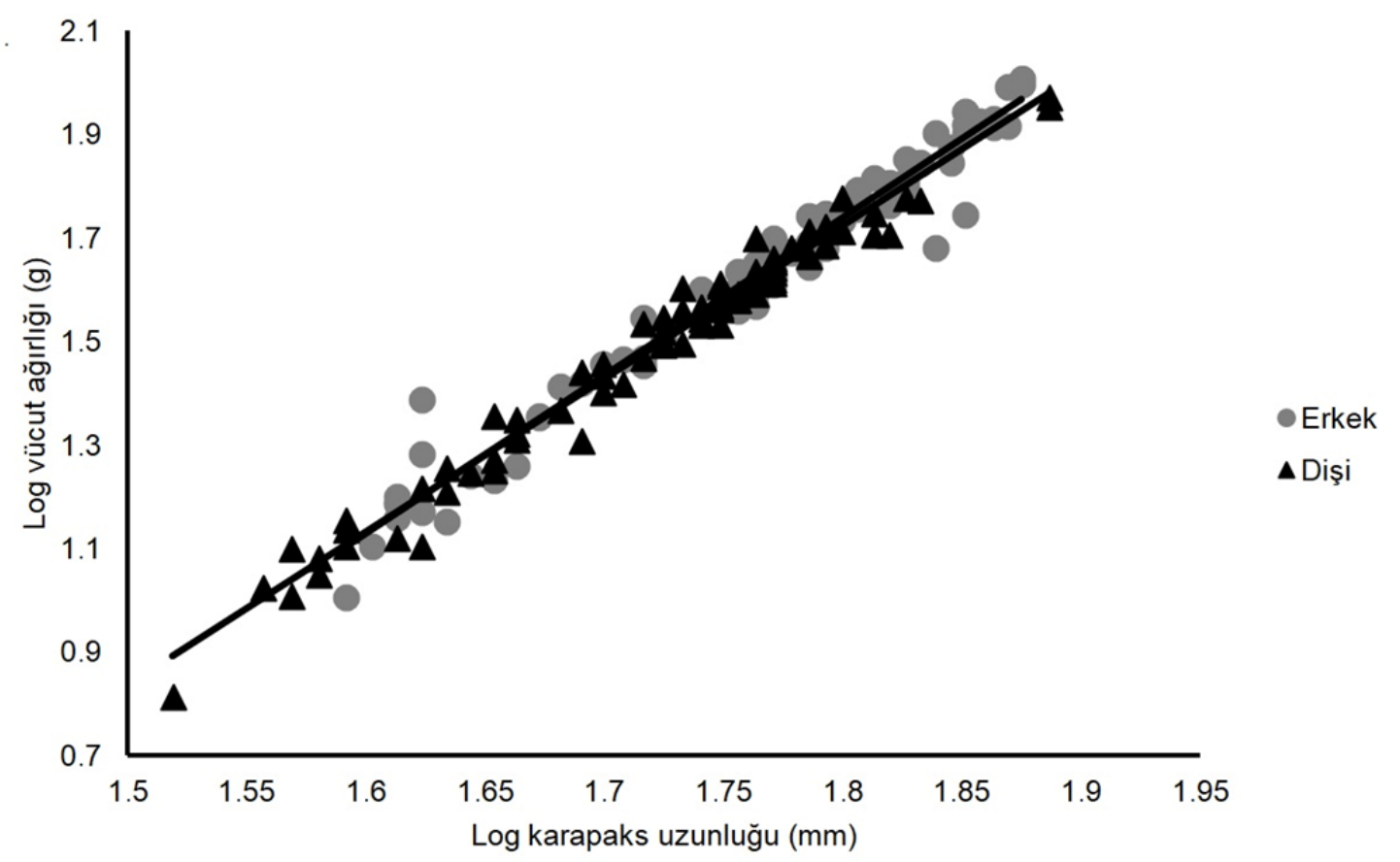

Şekil 3. Kerevitlerde karapaks uzunluğu ile ağırlık arasındaki ilişki.

Regresyon analizleri sonucunda elde edilen "b değerleri” erkek kerevitlerde pozitif, dişi kerevitlerde negatif ve tüm bireylerde ise pozitif allometrik ağırlık artışının olduğunu göstermektedir (b değeri ${ }_{\delta}=3.041, \mathrm{~b}$ değeri ${ }_{+}=2.954 \mathrm{ve} \mathrm{b}$ değeri ${ }_{\delta+}=3.0167$ ).

\subsection{Et verimi}

Erkek ve dişi kerevitlerin abdomen, kıskaç ve toplam et miktarları incelendiğinde, erkek kerevitlerin et miktarlarının dişi kerevitlerden istatistiksel olarak önemli derecede daha fazla olduğu görüldü (Tablo 3).

Erkek ve dişi kerevitlerde abdomen et miktarları ile karapaks uzunlukları arasında doğrusal bir ilişkinin olduğu görülmekle beraber, bu ilişkinin erkek kerevitlerde daha güçlü olduğu tespit edildi (Şekil 4, Şekil 5). Kıskaç et miktarları ile karapaks uzunlukları arasındaki ilişsinin her iki eşeyde de çok güçlü olmadığı ve erkek kerevitlerde bu ilişkinin dişilere oranla daha yüksek olduğu belirlendi (Tablo 4). 
Tablo 3. Erkek ve dişi kerevitlerin ortalama et miktarları ve iki eşey arasındaki farklılığın istatistiksel derecesi.

\begin{tabular}{|c|c|c|c|}
\hline & Ortalama değerler \pm standard sapma (g) & $\begin{array}{l}\text { En küçük ve en } \\
\text { büyük değerler }\end{array}$ & $\begin{array}{c}\text { Farklilığın } \\
\text { istatistiksel } \\
\text { derecesi }\end{array}$ \\
\hline \multicolumn{4}{|c|}{ Abdomen et miktarı } \\
\hline Erkekler & $6.19 \pm 1.49$ & $3.8-10$ & \multirow{2}{*}{$\mathrm{P}<0.05$} \\
\hline Dişiler & $5.45 \pm 1.15$ & $3.4-8.7$ & \\
\hline \multicolumn{4}{|c|}{ Kıskaç et miktarı } \\
\hline Erkekler & $2.84 \pm 1.80$ & $0.4-7.2$ & \multirow{2}{*}{$\mathrm{P}<0.001$} \\
\hline Dişiler & $1.28 \pm 0.69$ & $0.4-2.8$ & \\
\hline \multicolumn{4}{|c|}{ Toplam et miktarı } \\
\hline Erkekler & $9.03 \pm 3.11$ & $4.3-17.2$ & \multirow{2}{*}{$\mathrm{P}<0.001$} \\
\hline Dișiler & $6.73 \pm 1.53$ & 4.4-10.2 & \\
\hline
\end{tabular}

Tablo 4. Kerevitlerin et miktarları ve karapaks uzunlukları arasındaki ilişkilerin denklemleri.

\begin{tabular}{ccc}
\hline $\log (\mathrm{y})$ & $\log (\mathrm{a})+\mathrm{b} \log (\mathrm{x})$ & $\mathrm{r}$ \\
\hline Erkek Abdomen & $\mathrm{y}=2.253 \mathrm{x}-3.300$ & 0.737 \\
Erkek Kiskaç & $\mathrm{y}=5.188 \mathrm{x}-9.036$ & 0.457 \\
Erkek Toplam & $\mathrm{y}=2.891 \mathrm{x}-4.266$ & 0.694 \\
\hline Dişi Abdomen & $\mathrm{y}=1.885 \mathrm{x}-2.625$ & 0.683 \\
Dişi Kiskaç & $\mathrm{y}=3.231 \mathrm{x}-5.708$ & 0.233 \\
Dişi Toplam & $\mathrm{y}=2.146 \mathrm{x}-2.998$ & 0.730 \\
\hline Tüm Bireyler Abdomen & $\mathrm{y}=2.034 \mathrm{x}-2.899$ & 0.727 \\
Tüm Bireyler Kiskaç & $\mathrm{y}=5.189 \mathrm{x}-9.098$ & 0.453 \\
Tüm Bireyler Toplam & $\mathrm{y}=2.891 \mathrm{x}-4.289$ & 0.729 \\
\hline
\end{tabular}

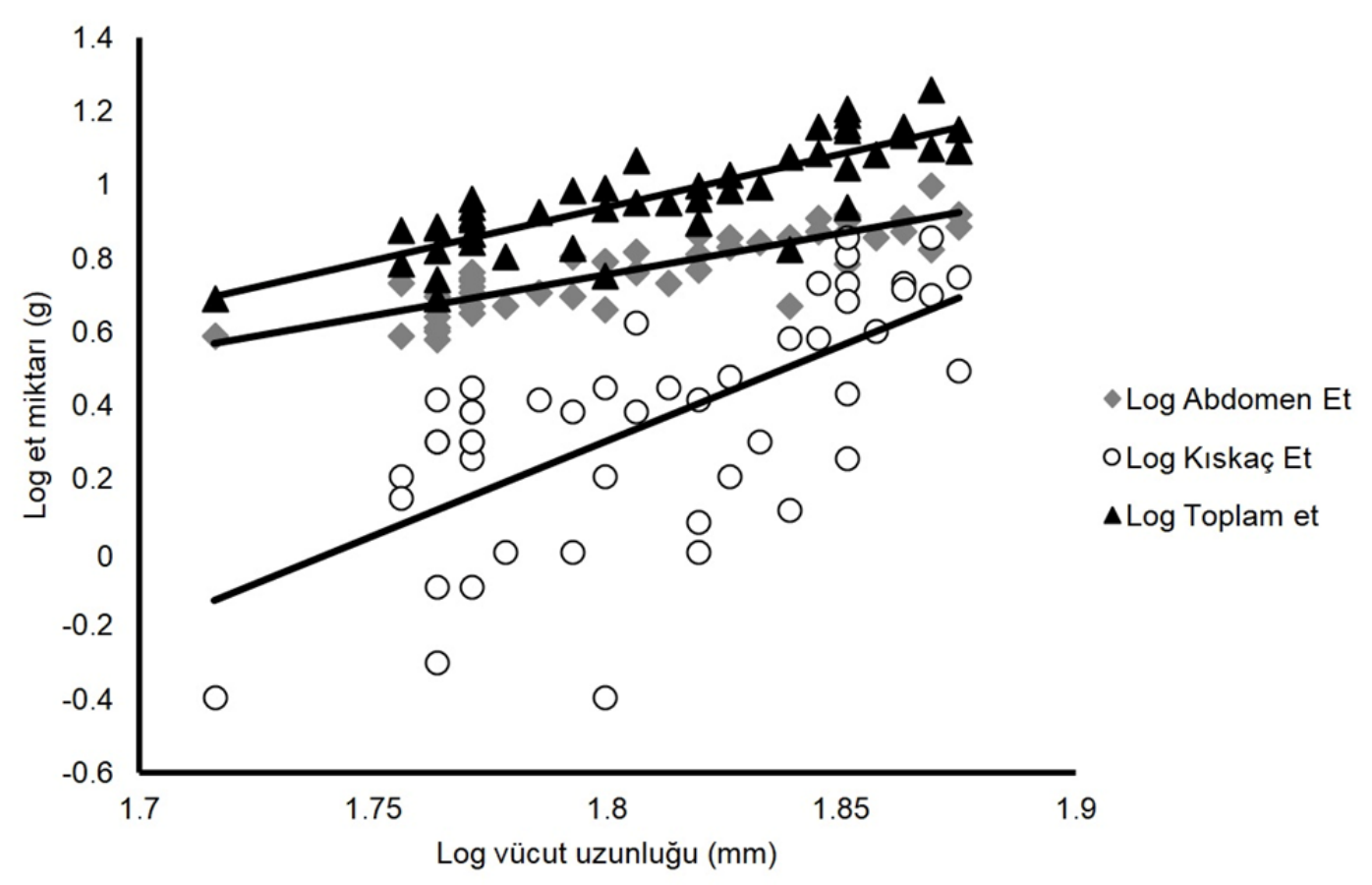

Şekil 4. Erkek kerevitlerde et miktarları ve karapaks uzunluğu arasındaki ilişki. 


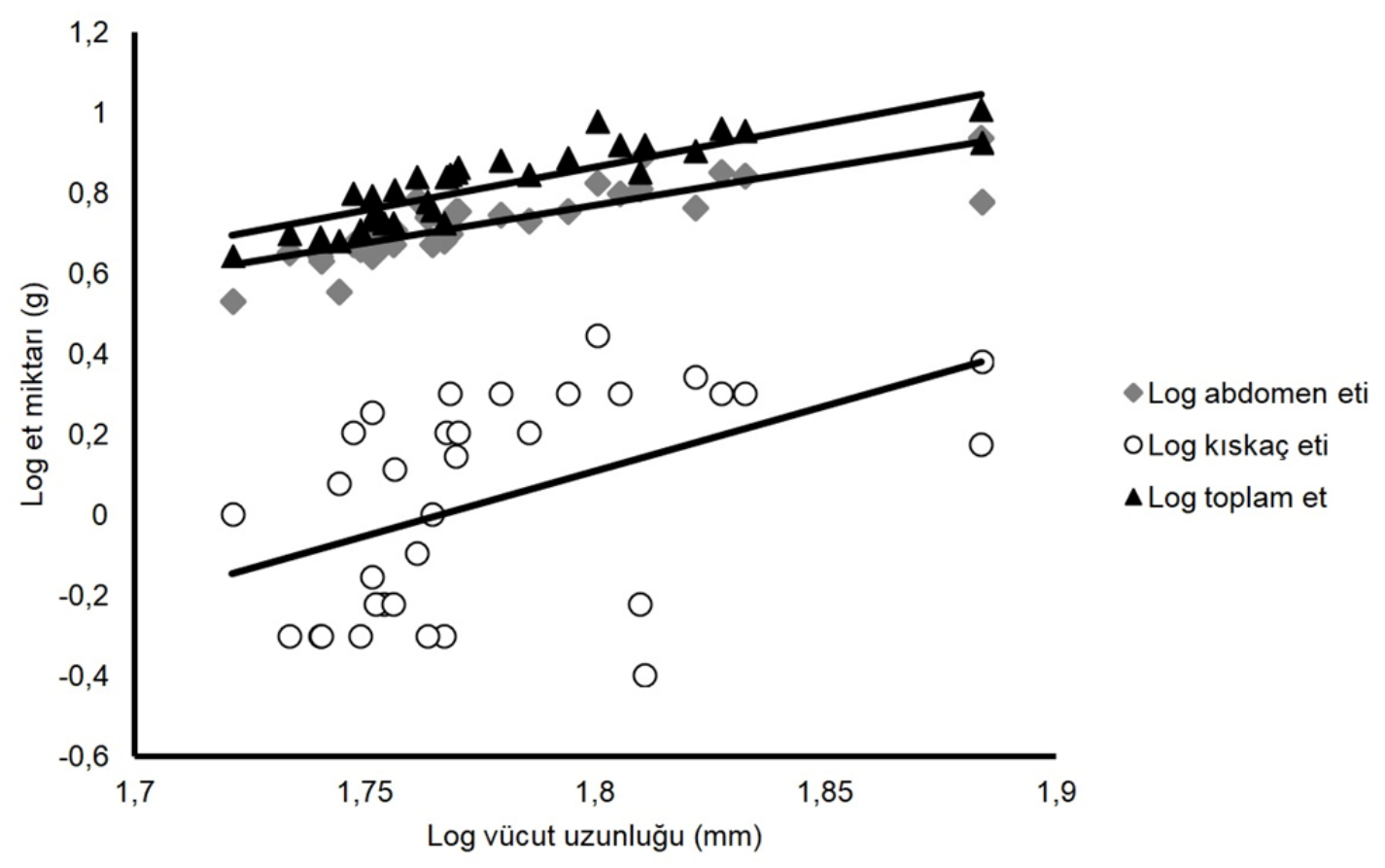

Şekil 5. Dişi kerevitlerde et miktarları ve karapaks uzunluğu arasındaki ilişki.

Et verimleri incelendiğinde, erkek kerevitlerin abdomen et verimlerinin $\% 10.03$, kıskaç et verimlerin $\% 4.60$ ve toplam et verimlerinin \% 14.63 olduğu, dişi kerevitlerin ise abdomen et verimlerinin \% 11.59, kıskaç et verimlerinin $\% 2.73$ ve toplam et verimlerinin $\% 14.32$ olduğu belirlendi.

\section{Tartışma ve sonuç}

Bu çalışmada diğer çalışmalar $[11,28,29,30]$ ile benzer şekilde erkek kerevitlerin dişi kerevitlerden istatistiksel olarak uzun ve ağır oldukları görülmüştür. Bununla beraber Eğirdir, Eber ve İznik Gölü kerevitlerinde dişi ve erkek kerevitlerin yaklaşık eşit uzunlukta olduğu, Terkos ile Akşehir Gölü ve Miliç Çayı kerevitlerinin dişilerinin erkeklerden daha uzun olduğu belirtilmiştir [31]. Diğer taraftan bütün populasyonlarda erkek bireyler dişi bireylerden ağır bulunmuştur. Dişi kerevitlerden daha küçük veya eşit uzunluktaki erkek kerevitlerin daha ağır olmasının nedeni ise daha uzun, geniş ve ağır kıskaçlarından kaynaklanmaktadır.

Bütün çalışmalar incelendiğinde uzunluk ve ağırlık dağılımında da aynı gölün çeşitli araştırmacılar tarafından elde edilen değerleri arasında farklılıklar vardır. Benzer şekilde aynı araştırmacının farklı göllerde veya aynı gölde değişik zamanlarda elde ettiği değerler arasında dahi farklar görülmüştür. $\mathrm{Bu}$ farklılığın sebebi farklı mevsimlerde farklı uzunluktaki kerevitlerin farklı derinliklerde ve farklı taban yapılarında bulunması, avlanma yönteminin farklılığ 1 ve bazı göllerde avcılık baskısının etkisi olabilir.

Bu çalışmada hem erkek ve hem de dişi kerevitlerin boy ve ağırlıkları arasında kuvvetli bir ilişki bulunmuştur. Başka araştırmacılar tarafından yapılan çalışmalarda [11, 26, 30, 32-35] benzer bulgular elde edilmiştir. 
Regresyon analizleri sonucunda elde edilen "b değerleri” erkek kerevitlerde pozitif, dişi kerevitlerde negatif ve tüm bireylerde ise pozitif allometrik ağırlık artışının olduğunu göstermektedir.

Diğer araştırmacılar [11, 26, 32-35] tarafından yapılan bazı çalışmalarda erkek, dişi ve tüm bireylerde negatif allometrik büyümenin olduğu tespit edilirken, başka araştırmalarda [36, 37] ise erkek kerevitlerin izometrik ve dişi kerevitlerin pozitif allometrik büyüme gösterdikleri bildirilmiştir ki, bu veriler bu çalışmada elde edilen bulgular ile farklılık göstermektedir. Yine başka çalışmalarda $[38,39]$ ise bu çalışmada olduğu gibi, erkek kerevitlerde pozitif allometrik ve dişi kerevitlerde negatif allometrik ağırlık artışının olduğu belirlenmiştir.

Eğirdir, İznik ve Hirfanlı göllerinde yapılan bir çalışmada, ortalama abdomen eti miktarı erkek bireylerde sirasıyla 3.93, 2.99 ve $3.46 \mathrm{~g}$, dişi bireylerde sırasıyla 4.49, 4.08 ve $3.53 \mathrm{~g}$ olarak bulunmuştur [40]. Gaga Gölü'nde yapılan bir çalışmada ortalama et miktarı erkeklerde 5.52 ve dişilerde $2.81 \mathrm{~g}$ olarak tespit edilmiştir [35]. Diğer çalışmalarda ortalama et miktarları bu çalışmada elde edilen değerlerden oldukça düşük bulunmakla beraber, bu farklılık ile ilgili olarak daha iyi yorum yapabilmek için et verim değerlerine de bakmak gerekmektedir.

Keban Baraj Gölü Çemişgezek bölgesinde yapılan iki farklı çalışmanın birincisinde [41], ortalama toplam et verimi erkek bireylerde \% 15.16 ve dişi bireylerde $\% 16.25$ olarak, ikinci çalışmada [42] ise erkek bireylerde \% 21.42 ve dişi bireylerde \% 21.02 olarak bulunmuştur. Mamasın Baraj Gölü'nde yapılan çalışmada erkek bireylerde \% 14.83 ve dişilerde \%12.76 olarak bulunmuştur [43]. Apolyont Gölü'nde yapılan çalışmada bu oran erkeklerde \%15.86 ve dişi bireylerde \%17.36 olarak tespit edilmiştir [44]. Gaga Gölü'nde erkek kerevitlerde \%19.70 ve dişilerde ise \%15.68 oranları elde edilmiştir [35].

$\mathrm{Bu}$ çalışmada elde edilen bulgular bir çalışma [42] dışında, diğer çalışmalarda elde edilen bulgulara yakındır. Bununla beraber az çok farklı değerlerin elde edilmiş olması gölün ekolojik özelliklerinin farklılı̆̆ından, avlanılan derinliklerin farklı olmasından veya avcılığın değişik zamanlarda yapılmış olmasından kaynaklanabilir. Özellikle üreme ve kabuk değiştirme dönemlerinin hemen ardından yapılan çalışmalarda çok farklı sonuçlar elde edilebilir. Keban Baraj Gölü Çemişgezek bölgesinde iki farklı araştırmacının elde ettiği bulguların dahi birbirinden oldukça farklı olduğu görülmüştür.

Eğirdir Gölü'nde boy uzunluğu $11 \mathrm{~cm}$ 'nin altında olan kerevitlerde 3-5 g. kadar et var iken, $11 \mathrm{~cm}$ üstünde ise et miktarının 8-12 g ağırlığa ulaştığı, dolayısıyla et miktarında $\%$ 100'e varan bir artış olduğu bulunmuştur. $11 \mathrm{~cm}$ altındaki kerevitlerin kelipet etlerinden yararlanılamamaktadır. $11 \mathrm{~cm}$ 'den daha küçük kerevitlerin avlanmasının yasaklanması kerevit populasyonunun daha da büyümesi ve yüksek et veriminin sağlanması için gereklidir [45].

Et miktarları bir gösterge olmakla beraber et verimliliğini tam olarak yansıtmamaktadır. Avlanan bireylerin büyüklük dağılımları et miktarları üzerinde etkili olacağından, temel veri olarak et miktarlarının değil de et veriminin alınması daha sağlıklı olacaktır. Örneğin Gaga Gölü kerevitlerinden elde edilen et miktarları bu çalışmada elde edilen et miktarlarından daha küçük iken, et verim oranları bu çalışmada elde edilen verilerden daha büyüktür. 
$\mathrm{Bu}$ çalışmada Aktaş Gölü'nde yaşayan kerevitlerin boy ve ağılıkları arasında çok kuvvetli doğrusal bir ilişkinin ve erkek bireylerin ortalama ağırlıklarının dişilere oranla daha fazla olduğu görülmüştür. Kerevitlerin et verimlerinin ise Türkiye'de yaşayan diğer kerevitlerin ortalama değerlerine yakın bir seviyede olduğu belirlenmiştir. Bu çalışma Aktaş Gölü kerevitleri üzerinde yapılan ilk çalışmadır ve daha sonra yapılacak çalışmalara önderlik edeceği düşünülmektedir.

\section{Teşekkür}

Ticari avcılığın yasak olduğu Aktaş Gölü'nde bu çalışmanın yapılabilmesi için gerekli izni veren, Gıda Tarım ve Hayvancılık Bakanlığı, Balıkçılık ve Su Ürünleri Genel Müdürlügü'ne (İzin Sayı No: 67852565/140.03.03-2351) ve MFTUB013-06 nolu projeye destek veren Munzur Üniversitesi Bilimsel Araştırma Projeleri Birimi'ne teşekkür ederiz.

\section{Kaynaklar}

[1] Hogger, J.B., Ecology, population biology and behaviour, in Holdich, D.M. and Lowery, R.S., Freshwater Crayfish, Biology, Menagement and Exploitation, Chapman and Hall, 114-144, Cambridge, England (1988).

[2] Momot, W.T., Redefining the role of crayfish in aquatic ecosystems, Reviews in Fisheries Science, 3, 1, 33-63, (1995).

[3] Harlığlu, M.M. ve Holdich, D.M., Meat yields in the introduced crayfish, Pacifastacus leniusculus and Astacus leptodactylus, from British waters, Aquaculture Research, 32, 411-417, (2001).

[4] Goddard, J.S., Food and Feeding, Holdich, D.M. and Lowery, R.S., Freshwater Crayfish, Biology, Menagement and Exploitation, Chapman and Hall, 145-166, Cambridge, England, (1988).

[5] Harlıoğlu, M.M. ve Köprücü, K., An investigation on the vitamin A2, C, E and $\beta$-carotene contents of freshwater crayfish, Astacus leptodactylus Eschscholtz., Fırat Üniversitesi Fen ve Mühendislik Bilimleri Dergisi, 12, 2, 277-281, (2000).

[6] Skurdal, J. ve Taugbøl, T., Crayfish of commercial importance Astacus, in Holdich, D.M., Biology of Freshwater Crayfish, Blackwell Science, 467-510, Oxford, (2002).

[7] Utku, G. ve Harlioğlu, M.M., Status of freshwater crayfish distribution in Thrace region of Turkey, Reviews in Fisheries Science, 18, 1, 1-6, (2009).

[8] Harlığlu, M.M. ve Güner, U., A new record of recently discovered crayfish, Austropotamobius torrentium (Shrank, 1803), in Turkey, Bulletin Français de la Pêche et de la Pisciculture, 387, 1-5, (2007).

[9] Harlıoğlu, M.M. ve Güner, U., Studies on the recently discovered crayfish, Austropotamobius torrentium (Shrank, 1803), in Turkey: morphological analysis and meat yield, Aquaculture Research, 37, 538-542 (2006).

[10] Köksal, G., Astacus leptodactylus in Europa, Freshwater Crayfish, Biology, Menagement and Exploitation, in Holdich, D.M. and Lowery, R.S., Freshwater Crayfish, Biology, Menagement and Exploitation, Chapman and Hall, 365-400, Cambridge, England, 498p, (1988). 
[11] Bolat, Y., Eğirdir Gölü Hoyran Bölgesi tatlı su istakozlarının (Astacus leptodactylus salinus Normdan 1842) populasyon büyüklüğünün tahmini, Doktora Tezi, Süleyman Demirel Üniversitesi, Fen Bilimleri Enstitüsü, Isparta, (2001).

[12] Burba, B., Investigations of the effects of anthropogenic factors on crayfish behavioural reactions, Freshwater Crayfish, 9, 259-265, (1993).

[13] Lodge, D.M. ve Hill, A.M., Factors governing species composition, population size, and productivity of cool-water crayfishes, Nordic Journal Freshwater Research, 69, 111-136, (1994).

[14] Harlığlu, M.M., Tatlı su istakozu yetiştiriciliği, Fırat Üniversitesi Yayın Komisyonu Başkanlığı, Elazığ, (2004).

[15] Mason, J.C., Crayfish production in a small woodland stream, Freshwater Crayfish, 2, 449-479, (1975).

[16] Stein, R.A., Sexual dimorphizm in crayfish chelae: functional significance linked to reproductive activites, Canadian Journal of Zoology, 54, 220-227, (1976).

[17] Adegboye, D., The "crayfish condition factor": a tool in crayfish research, Freshwater Crayfish, 5, 3-11, (1983).

[18] Skurdal, J., Crayfish Management in the Nordic and Baltic countries, Nordic Journal Freshwater Research, 69, 181-184, (1994).

[19] Pursiainen, M., Saarela, M. ve Westman, K., Moulting and growth of the noble crayfish Astacus astacus in an oligotrophic lakle, Freshwater Crayfish, 7, 155164, (1988).

[20] Rhodes, C.P. ve Holdich, D.M., On size and sexuel dimorphism in Austropotamobius pallipes (Lereboullet) - A step in assessing the commercial exploitation potential of the native British freshwater crayfish, Aquaculture, 17, 345-358, (1979).

[21] Lindqvist, O.V. ve Lahti, E., On the sexuel dimorphism and condition indexs in the crayfish Astacus astacus L. in Finland, Freshwater Crayfish, 5, 3-11, (1983).

[22] Harlığlu, M.M., Keban Baraj Gölü Ağın bölgesinde yaşayan tatlı su ıstakozu Astacus leptodactylus (Eschscholtz, 1823)'un alt tür teşhisi, İstanbul Üniversitesi Su Ürünleri Dergisi, 14, 31-47, (2002).

[23] Doğanay, H. ve Zaman, S., Aktaş Gölü ve yakın çevresinin coğrafyası, Türk Coğrafya Dergisi, 46, 23-39, (2006).

[24] http://cografyaharita.com/haritalarim/2eturkiye-akarsular-haritasi.png, (19.10.2017).

[25] Rhodes, C.P. ve Holdich, D.M., Length-weight relationship, muscle production and proximate composition of the freshwater crayfish Austropotamobius pallipes (Lereboullet), Aquaculture, 37, 107-123, (1984).

[26] Harlıoğlu, M.M., The relationships between length-weight, and meat yield of freshwater crayfish, Astacus leptodactylus Eschscholtz, in the Ağın Region of Keban Dam Lake, Turkish Journal of Zoology, 23, 3, 949-957, (1999).

[27] Romaire, R.P., Forester, J.S. ve Avault, J.V., Length-weight relationships of two commercially important crayfishes of the genus Procambarus, Freshwater Crayfish, 3, 463-470, (1977).

[28] Erdemli, A.Ü., Beyşehir, Eğirdir, Akşehir ve Apa baraj gölü tatlı su istakozlarının (Astacus leptodactylus Esch., 1823) populasyonları üzerine karşılaştırmalı bir araştırma, Doğa Bilim Dergisi, 7, 313-318, (1983). 
[29] Karabatak, M. ve Tüzün, İ., Mogan Gölü'ndeki kerevit (Astacus leptodactylus Eschscholtz, 1823) populasyonunun bazı özellikleri, Akdeniz Üniversitesi Su Ürünleri Mühendisliği Dergisi, 2, 1-34, (1989).

[30] Güner, U., Kavakl1 Göleti (Edirne-Meriç) kerevitleri Astacus leptodactylus (Eschscholtz, 1823)'un bazı morfolojik özellikleri ile büyüme parametreleri, Biyoloji Bilimleri Araştırma Dergisi, 1, 1, 37-42, (2008).

[31] Köksal, G., Biometric analysis on the freshwater crayfish (Astacus leptodactylus Eschscholtz, 1823) which is produced in Turkey, relationship between the major body components and meat yield, Ankara Üniversitesi Veteriner Fakültesi Dergisi, 26, 3-4, 93-114, (1980).

[32] Bolat, Y. ve Aksoylar, M.Y., Eğirdir gölü kerevitleri (Astacus leptodactylus Esch., 1823)'nin uzunluk ağırlık ile karapaks boyu-total boy ilişkileri ve kabuk değiștirme periyodunun saptanması, Eğirdir Su Ürünleri Fakültesi Dergisi, 2, 10, 26-31, (2003).

[33] Balık, İ., Çubuk, H., Özkök, R. ve Uysal, R., Some biological characterics of crayfish (Astacus leptodactylus Eschscholtz, 1823) in Lake Eğirdir, Turkish Journal of Zoology, 29, 295-300, (2005).

[34] Güner, U., Terkos Gölü kerevitleri (Astacus leptodactylus Eschscholtz, 1823)'nin bazı morfolojik özellikleri, Ege Üniversitesi Su Ürünleri Dergisi, 23, 1-2, 163-167, (2006).

[35] Yılmaz, E., Harlıoğlu, A.G. ve Yılmaz, A., Gaga Gölü (Ordu, Türkiye)'nden yakalanan tatlisu 1stakozu (Astacus leptodactylus Eschscholtz, 1823)'nda ağırlık-uzunluk ilişkisi ve et verimi, Su Ürünleri Dergisi, 28, 3, 75-80, (2011).

[36] Köksal, G., Korkmaz, A.Ş. ve Kırkağaç, M., Anakara Dikilitaş Göleti tatlı su istakozu (Astacus leptodactylus Eschscholtz, 1823) populasyonunun incelenmesi, Tarım Bilimleri Dergisi, 9, 1, 51-58, (2003).

[37] Berber, S. ve Balık, S., Manyas Gölü (Balıkesir) tatlı su ıstakozunun (Astacus leptodactylus Eschscholtz, 1823) bazı büyüme ve morfometrik özelliklerinin belirlenmesi, Ege Üniversitesi Su Ürünleri Dergisi, 23, 1-2, 83-91, (2006).

[38] Dartay, M. ve Ateşşahin, Y., A study on catching freshwater crayfish, Astacus leptodactylus Eschscholtz 1823, and its some population characteristics, Turkish Journal of Science and Technology, 8, 2, 125-130, (2013).

[39] Yüksel, F. ve Duman, E., Keban Baraj Gölü kerevitlerinin (Astacus leptodactylus Esch., 1823) bazı morfolojik özelliklerinin incelenmesi, Journal of Fisheries Sciences.com, 6, 4, 271-281, (2012).

[40] Harlıoğlu, M.M. ve Harlığlu, A.G., Eğirdir, İznik Gölleri ve Hirfanlı Baraj Gölü'nden avlanan tatlı su istakozu Astacus leptodactylus (Eschscholtz, 1823)'un morfometrik analizleri ile et verimlerinin karşılaştırılması, Fırat Üniversitesi Fen ve Mühendislik Bilimleri Dergisi, 17, 2, 412-423, (2005).

[41] Barım, Ö., Keban Baraj Gölü, Çemişgezek Bölgesi tatlı su istakozu, Astacus leptodactylus Eschscholtz, 1823'un morfometrik analizi ve et verimi, Firat Üniversitesi Fen ve Mühendislik Bilimleri Dergisi, 19, 3, 301-307, (2007).

[42] İnanlı, A.G. ve Çoban, Ö.E., Keban Baraj Gölü Çemişgezek Bölgesi'ndeki tatlı su istakozlarının (Astacus leptodactylus Esch., 1823) et verimi ve kimyasal kalitesi, Doğu Anadolu Bölgesi Araştırmaları Dergisi, 79-82, (2007).

[43] Büyükçapar, H.M., Alp, A., Kaya, M. ve Çiçek, Y., Mamasın Baraj Gölü (Aksaray-Türkiye) tatlisu istakozu (Astacus leptodactylus Eschscholtz, 1823)'nun boy-ağırlık ilişkisi ve et verimi, Ege Üniversitesi Su Ürünleri Dergisi, 23, 1-2, 21-25, (2006). 
[44] Berber, S. ve Balık, S., Apolyont Gölü (Bursa-Türkiye) tatlısu istakozunun (Astacus leptodactylus eschscholtz, 1823) boy-ağırlık ilişkisi ve et verimi, Journal of Fisheries Sciences.com, 3, 2, 86-99, (2009).

[45] Yıldırım, Z.M., Gülyavuz, H. ve Ünlüsayın, M., Eğirdir gölü kerevitlerinin (Astacus leptodacytlus salinus Nordman, 1842) et verimi üzerine bir araştırma, Turkish Journal of Zoology, 21, 101-105, (1997). 